\title{
Temperature and color management of silicon solar cells for building integrated photovoltaic
}

\author{
Mohamed Amara ${ }^{1}$, Fabien Mandorlo, ${ }^{2}{ }^{*}$, Romain Couderc ${ }^{1}$, Félix Gérenton ${ }^{2}$, and Mustapha Lemiti ${ }^{2}$ \\ ${ }^{1}$ Univ Lyon, CNRS, INSA-Lyon, Université Claude Bernard Lyon 1, CETHIL UMR5008, 69621 Villeurbanne, France \\ ${ }^{2}$ Université de Lyon, Institut des Nanotechnologies de Lyon INL - UMR5270 CNRS INSA Lyon, 69621 Villeurbanne, France
}

Received: 27 March 2017 / Received in final form: 12 July 2017 / Accepted: 7 September 2017

\begin{abstract}
Color management of integrated photovoltaics must meet two criteria of performance: provide maximum conversion efficiency and allow getting the chosen colors with an appropriate brightness, more particularly when using side by side solar cells of different colors. As the cooling conditions are not necessarily optimal, we need to take into account the influence of the heat transfer and temperature. In this article, we focus on the color space and brightness achieved by varying the antireflective properties of flat silicon solar cells. We demonstrate that taking into account the thermal effects allows freely choosing the color and adapting the brightness with a small impact on the conversion efficiency, except for dark blue solar cells. This behavior is especially true when heat exchange by convection is low. Our optical simulations show that the perceived color, for single layer ARC, is not varying with the position of the observer, whatever the chosen color. The use of a double layer ARC adds flexibility to tune the wanted color since the color space is greatly increased in the green and yellow directions. Last, choosing the accurate material allows both bright colors and high conversion efficiency at the same time.
\end{abstract}

Keywords: CIE 1931 color space / BIPV / thermal management / operating temperature / ARC / conversion efficiency / silicon solar cell

\section{Introduction}

Building integrated photovoltaics (BIPV) [1] is one of the solutions to support and develop renewable and nonpolluting energy. As a rule, performances of solar panels depend on the material quality and solar cells architecture, but also on cell temperature condition since high temperature degrades the conversion efficiency [2]. Nowadays, under the present conditions, the BIPV are not favorable to the cooling of solar cells. In addition, the esthetics of the PV panels must also be taken into account, including their color related to the urban environment.

In order to determine the cell or module operating temperature, it is possible to use experimental correlation such as those listed and discussed in the review of Skoplaki and Palyvos [3] and Kurnik et al. [4]. Even if these correlations calculate the module temperature as function of environmental conditions, they do not make it possible to link the thermal equilibrium as a function of the cells characteristics, in particular the anti-reflective layers. Moreover, the optimization of solar cells is done at

\footnotetext{
* e-mail: fabien.mandorlo@insa-lyon.Fr
}

standard test conditions (STC, $25^{\circ} \mathrm{C}$ ) which ignores the actual temperature of the cell. It is necessary to use a thermal model in addition to the electro-optical ones to take into account heat exchange in order to calculate the operating temperature.

To adjust the perceived color of a solar cell observed outside a building, we can control the reflection on its top surface, and so adjust the thickness of the anti-reflective coating (ARC) layers [5]. Such a solution is both easy and flexible since we only need to control the duration of a deposited layer. However, we have to balance between the brightness/contrast of the reflected light, and the number of photons producing the electrons and holes. Indeed, maximizing the short circuit current $J_{s c}$, which corresponds to the number of carriers that are photogenerated and collected in electrodes, is a simple way to optimize the conversion efficiency at STC [6-9] for which the solar cell is cooled at the ambient temperature $25{ }^{\circ} \mathrm{C}$, with no heat transfer. In real configurations, thermal conditions and solar irradiation are major varying factors that strongly affect the conversion efficiency of photovoltaic cells. As a consequence, thermal effects are likely to be required for the optimization analysis of ARC layers of PV cells. It is clear from this observation that the obvious criterion is the maximization of the electrical conversion efficiency. 
Ideally, the aim is to satisfy two conflicted requirements: obtain both the wanted colors and a high conversion efficiency.

In this article, we propose to determine the influence of the ARC thickness on the color and conversion efficiency taking into account the thermo-electro-optical properties.

\section{Modeling of solar cells performances and colors}

\subsection{Solar cell simulation}

For cell simulation, we use our in-house computer simulation tool [10] based on the resolution of three interdependent physical aspects. The first one is the heat transfer, which includes the following source terms: local heat due to radiation absorption and thermal emission $\left(Q_{R}\right)$, non-radiative recombination $\left(Q_{N R R}\right)$, excess power released by thermalization $\left(Q_{T}\right)$, Joule effect $\left(Q_{J}\right)$ which corresponds to the interaction between the charge carriers current and the electrical field inside the cell, and Thomson effect $\left(Q_{T M}\right)$ due to the heat carried and extracted from the cell by the charge carriers. The second set is a spectral radiative transfer, which is solved through a gray per band approach and separated treatments of the direct and diffuse components of radiation fluxes. The third set of equations is related to generation and diffusion of electrons and holes in the device.

All the equations are solved with spectral and thermal variation of all used parameters. So, in range $[0.2-15] \mu \mathrm{m}$, the incident spectrum is decomposed in several spectral bands. For the boundary conditions, in addition to the front and back surface recombination velocity respectively, we take into account current flow at metal-semiconductor interfaces thanks to the Peltier effect $\left(Q_{P}\right)$ and the heat exchange by convection $\left(Q_{\text {Conv }}\right)$.

\subsection{Optical calculation: conversion of an optical spectrum to a color in the CIE 1931 color space}

In this part we focus on the color prediction of a solar cell, by using its reflected spectrum. The CIE 1931 XYZ color space has been created by the International Commission on Illumination (CIE) [11] in 1931 in order to link the visible spectrum with the perceived colors of the human eye. To match the sensitivity of the short-middle-long wavelength of "standard" human cone cells, this color space relies on 3 color matching functions $\bar{x}(\lambda), \bar{y}(\lambda)$, and $\bar{z}(\lambda)$ (Fig. 1 ).

These functions are used to calculate the tristimulus values $X, Y$ and $Z$ by projection of the optical signal to be converted $S(\lambda)$ on the visible range from 380 to $780 \mathrm{~nm}[12]$. For this article, the optical signal $S(\lambda)$ will be the reflected light $(R(\lambda))$ coming from a normalized power density spectrum $\operatorname{AM}_{x}(\lambda)$, leading to $S(\lambda)=R(\lambda) \cdot A M_{x}(\lambda)$ :

$$
\left\{\begin{array}{l}
X=W^{-1} \cdot \int_{380}^{780} \bar{x}(\lambda) \cdot S(\lambda) \cdot d \lambda \\
Y=W^{-1} \cdot \int_{380}^{780} \bar{y}(\lambda) \cdot S(\lambda) \cdot d \lambda \\
Z=W^{-1} \cdot \int_{380}^{780} \bar{z}(\lambda) \cdot S(\lambda) \cdot d \lambda
\end{array}\right.
$$

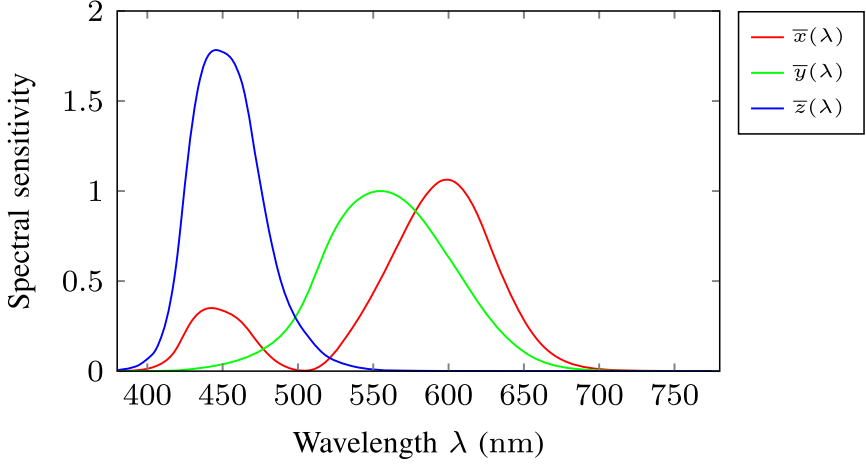

Fig. 1. CIE 1931 standard observer color matching functions.

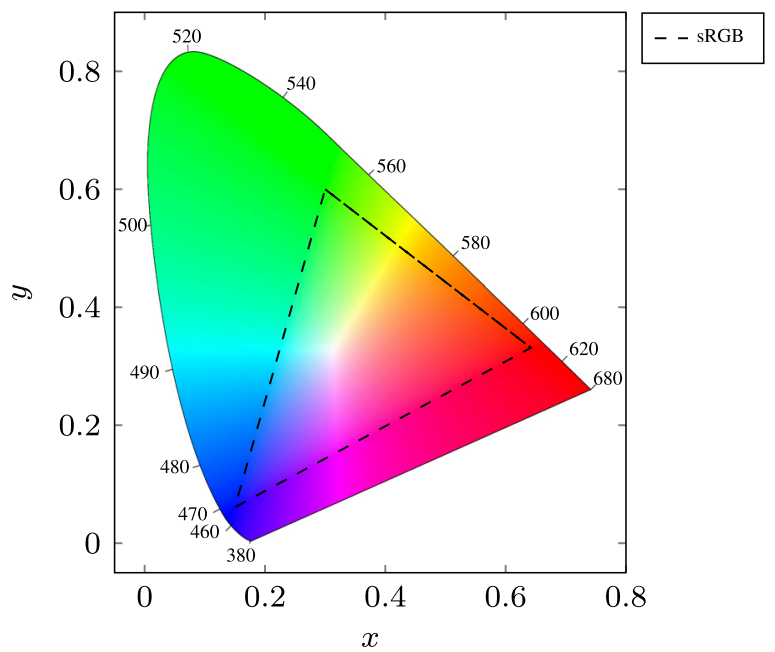

Fig. 2. CIE1931 color space chromaticity diagram including the sRGB one (used for displays).

with:

$$
W=\int_{380}^{780} \bar{y}(\lambda) \cdot A M_{x}(\lambda) \cdot d \lambda
$$

Among coordinates $(X, Y, Z), Y$ represents the brightness of the signal, since the human eyes perceive light mainly through the middle range cone cells, which correspond to the green color detection. This parameter necessarily varies between 0 (no visible light) and 1 (all visible light is reflected). The chromaticity of a color, that quantifies the balance between each elementary wavelengths of the signal, is described by two derived parameters $x$ and $y$ defined such as:

$$
x=\frac{X}{X+Y+Z} \quad \text { and } \quad y=\frac{Y}{X+Y+Z} .
$$

Then, $x, y$ and $Y$ scalars correspond to the CIE 1931 xyY color space. Its chromaticity diagram, also called gamut (Fig. 2) represents the domain covered by $x$ and $y$ for any visible signal: it is delimited by the single wavelength optical signals and any linear combination of the 380 and $780 \mathrm{~nm}$ ones (also called the "purple line"). 


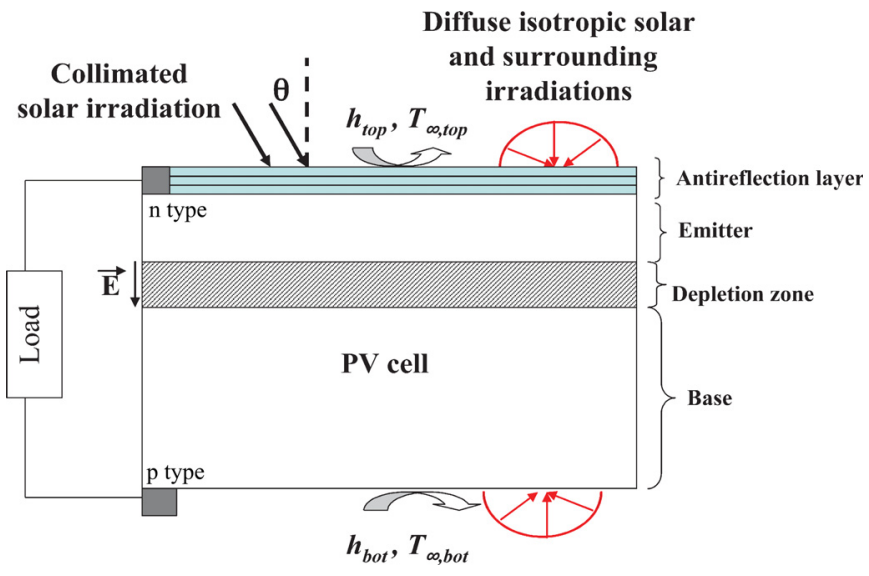

Fig. 3. Description of the simulated solar cell and its boundary conditions.

We can also use the tristimulus values to convert them into the sRGB system using [13] to calculate the Red, Green and Blue (RGB) coordinates for computers and displays. As this color space is smaller than the CIE 1931 xyY one (Fig. 2), colors out of the sRGB domain are approximated: the perceived color on a display (and so on this article) is slightly different from the real color of the simulated structure.

\section{Simulation inputs parameters}

\subsection{Description of the reference solar cell}

A non-encapsulated flat photovoltaic cell is considered with a generic structure composed of a standard $\mathrm{p}-\mathrm{n}$ junction with a negatively doped upper zone (n-type, emitter), a positively doped lower zone (p-type, base) and a depletion zone or charge space (Fig. 3).

In addition, the front surface is covered by a stack of dielectric thin films (ARC) in order to minimize the reflection of the incident light. The cell's upper face is subject to collimated and diffuse isotropic solar irradiations. The incidence of collimated beam is characterized by the incidence angle $\theta$. Additional diffuse isotropic radiation fluxes are considered at both boundaries and refer to surroundings' infrared radiation emission. The surroundings are considered as black bodies at $T_{+\infty, t o p}$ and $T_{+\infty, b o t}$ and the ambient temperature is noted $T_{a m b}$. To get the optical response of the ARC stack on the solar cell, we use the transfer matrix formalism [14] that has been validated by comparison with [15] to calculate the reflected spectrum of a multi-stack system and convert it into the CIE 1931 xyY color space. The studied cell has the parameters given in Table 1.

The used incident spectrum is a standard $\mathrm{AM}_{1.5 G}[16]$. The influence of air mass is investigated by also using $\mathrm{AM}_{1 G}$ and $\mathrm{AM}_{3 G}$ spectra (Fig. 4). As for the coefficient of convection on each side of the module $h_{\text {conv }}$, its value depends on the configuration of the module integration. Thus, there are many empirical correlation depending on the wind velocity (forced convection) or ambient temperature (free convection). For example, Jones and Underwood analysis [17] indicates a large variation of the
Table 1. Parameters and their default values used in simulation.

\begin{tabular}{ll}
\hline Wafer thickness & $250 \mu \mathrm{m}$ \\
Base doping (p-type, uniform) & $1 \times 10^{15} \mathrm{~cm}^{-3}$ \\
Emitter doping (n-type, uniform) & $1 \times 10^{19} \mathrm{~cm}^{-3}$ \\
Junction depth & $300 \mathrm{~nm}$ \\
Volume SRH lifetime & $1 \mathrm{~ms}$ \\
Front surface recombination velocity & $1000 \mathrm{~cm} \cdot \mathrm{s}^{-1}$ \\
Rear surface recombination velocity & $10000 \mathrm{~cm} \cdot \mathrm{s}^{-1}$ \\
Inclination $\theta$ & $0{ }^{\circ}$ \\
Top surrounding temperature & $25^{\circ} \mathrm{C}$ \\
$T_{+\infty, t o p}$ & \\
Bottom surrounding temperature & $25^{\circ} \mathrm{C}$ \\
$T_{+\infty, b o t}$ & \\
Ambient temperature $T_{a m b}$ & $25^{\circ} \mathrm{C}$ \\
Emissivity in silicon $\varepsilon_{S i}$ & 0.8 \\
\hline
\end{tabular}

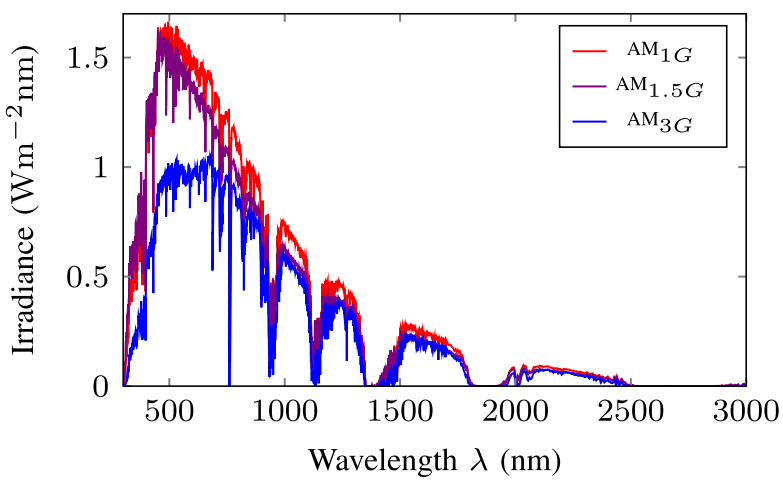

Fig. 4. Spectral irradiances for different air masses.

heat coefficient in between 1.2 and $9.6 \mathrm{~W} \cdot \mathrm{m}^{-2} \cdot \mathrm{K}^{-1}$. The last value corresponds to forced convection condition which is greatly favorable to the cooling of the modules. Inorder to evaluate the impact of ARC on the cell temperature, we choose two values of $h_{c o n v}: 2$ and $5 \mathrm{~W} \cdot \mathrm{m}^{-2} \cdot \mathrm{K}^{-1}$, which corresponds respectively to disadvantageous and favorable cooling conditions. In case of standard conditions, $h_{\text {conv }}$ is equal to $+\infty$ leading to an operating temperature of $25^{\circ} \mathrm{C}$ equal to the temperatures $T_{+\infty, t o p}, T_{+\infty, b o t}$ and $T_{a m b}$.

\subsection{Optical and thermophysical properties}

In this article, we use two types of data: experimental measurements and databases (Fig. 5). To calculate the infrared radiation emission and exchange with the atmosphere, we need to know the dispersion curve of all the materials until $\lambda=15 \mu \mathrm{m}$. Only few materials are known from visible to long wavelength infrared. Due to the lack of experimental data for other materials, we decide to use Philipp [18] and Kischkat et al. [19] for $\mathrm{SiO}_{2}$. As for $\mathrm{Si}_{3} \mathrm{~N}_{4}$, we use the data given by Gao et al. [20] and Kischkat et al. [19]. It should be noted that the concatenation procedure of these data creates a discontinuity for $\mathrm{Si}_{3} \mathrm{~N}_{4}$ at $1.5 \mu \mathrm{m}$. However, around this value, there is no impact on optical absorption and thermal behaviors. 

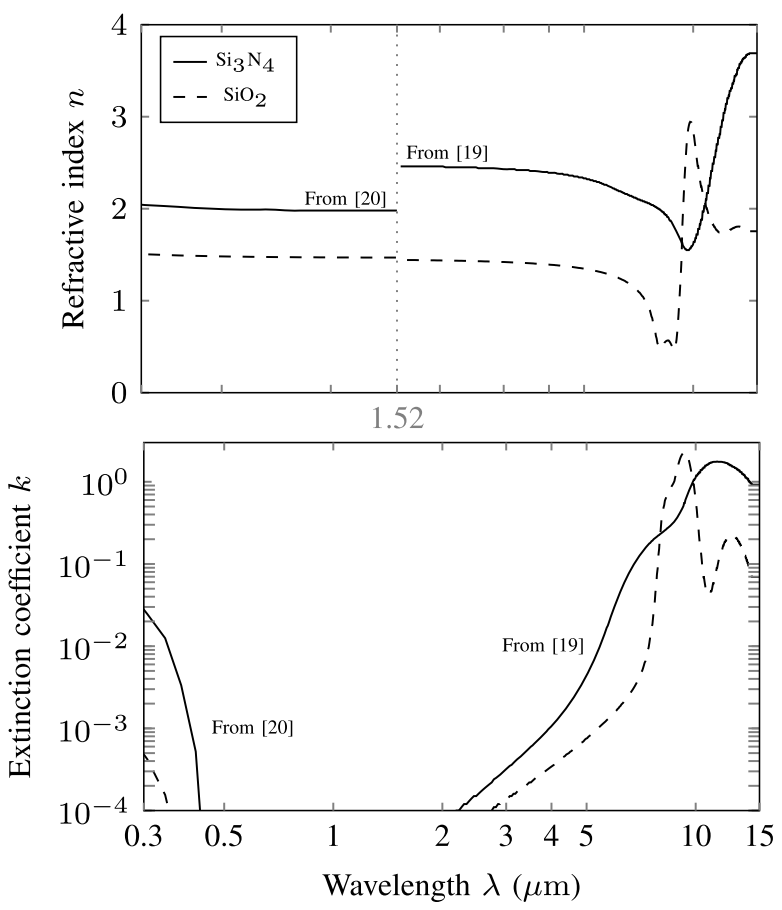

Fig. 5. Refractive index of $\mathrm{SiO}_{2}$ and $\mathrm{Si}_{3} \mathrm{~N}_{4}$ to cover both the visible and long wavelength infrared domains (data extracted from $[18-20])$.

Nevertheless, industrial solar cells are based on hydrogenated $\mathrm{SiN}_{x}$ and $\mathrm{SiO}_{x}$. In order to predict colors with these materials, we will use experimental data in the visible range. For this purpose, both $\mathrm{SiO}_{x}: \mathrm{H}$ and $\mathrm{SiN}_{x}: \mathrm{H}$ layers are deposited by LF-PECVD with different stoichiometries [21,22]. One of the $\mathrm{SiN}_{x}: \mathrm{H}$ layers ( $n=2.08$ at $\lambda=600 \mathrm{~nm}$ ) is optimized for both passivation and optical efficiency for standard flat silicon solar cells with no glass and no EVA. Then, a Horiba Jobin Yvon UVISEL ellipsometer is used to extract their optical indexes in the visible range (Fig. 6).

To take into account the temperature variation of the semiconductor models, we implement Fermi-Dirac free carriers statistics, free-carriers mobility [23], intrinsic carrier density [24], bandgap and bandgap narrowing [25,26] with temperature dependent models. Last, the transport of photogenerated carriers is governed by a standard diode equation. Details related to the determination of the band gap, optical and radiation properties, minority carrier diffusion coefficients, recombination rates and intrinsic concentrations can be found in our previous paper [24].

\section{Results and discussion}

\subsection{Achievable color space depending on the position of the observer}

In order to design colored solar cells, we propose to study both the thickness $t_{A R C}$ of a single layer ARC and the influence of the observation angle of an illuminated solar cell by an $\mathrm{AM}_{1.5 G}$ spectrum.

The theoretical result for a $\mathrm{Si}_{3} \mathrm{~N}_{4}$ ARC layer is shown in Figure 7a. The chromaticity is compatible with Figure 7 in

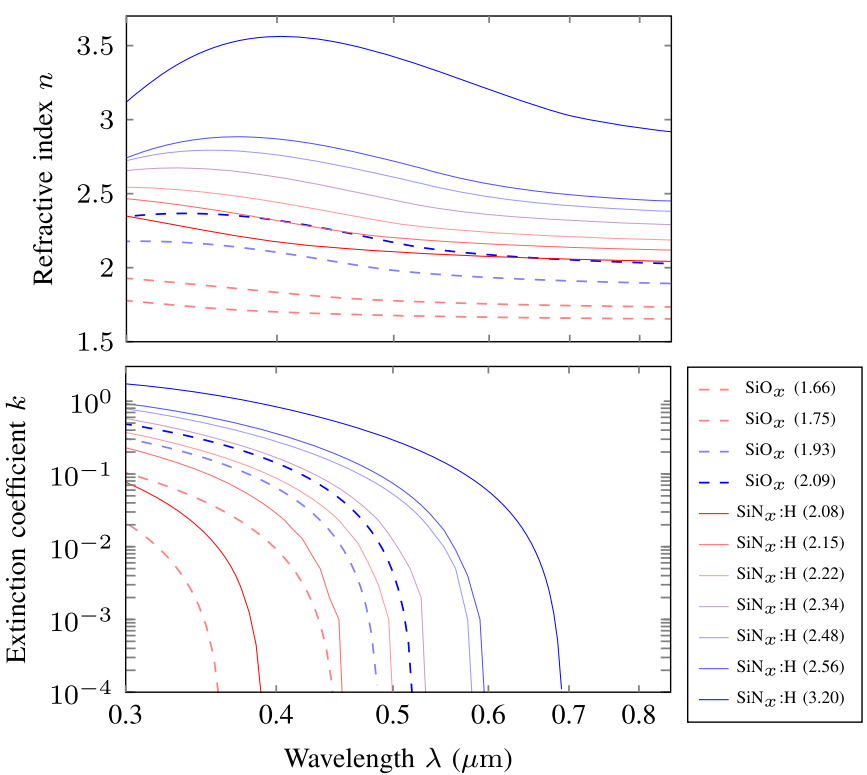

Fig. 6. Experimental optical indexes of different silicon oxides and nitrides (refractive index $n$ at $\lambda=600 \mathrm{~nm}$ in brackets).

[27] or Figure 2b in [9] for the normal reflection $(\theta=0)$. We observe that for a thin ARC (single mode regime), the color (Fig. 7a) and the brightness (Fig. 7b) are almost independent from the inclination of the solar cell. When the optical path of photons in the ARC layer is very long (i.e. for very high values of $\theta$ or $t_{A R C}$ ), the higher number of interferences lowers the color selectivity and the emitted light is close to a dark gray ( $Y$ close to $25 \%$ ).

From Figure 7b, the brightness (and so the contrast), gets its minimum and maximum values for $\theta=0$. We can also observe that colored cells are quite dark since the domain where the perceived colors are different from gray (Fig. 7a) correspond to the minimum domains of the brightness $Y$ (Fig. 7a). Figure 8 represents the chromaticity of the calculated colors. The dotted black line corresponds to the evolution of the color for a $75 \mathrm{~nm}$ thick $\mathrm{ARC}$, from an inclination from $0^{\circ}$ to $85^{\circ}$. With such a thickness, the solar cell is blue when observed with an $\mathrm{AM}_{1.5 G}$ irradiance and its color varies in direction of the gray point $x \approx y \approx 0.33$ when $\theta$ increases. This particular trend is verified whatever the thickness of the ARC. Consequently, drawing the chromaticity for $\theta=0$ can be used to get all the achievable colors for a single layer ARC.

Figure 8 also shows that a small part of the visible colors can be obtained with a silicon nitride ARC, with ability to reproduce dark-blue colors. Indeed, a standard $75 \mathrm{~nm}$ thick ARC (point $B_{1}$ in Fig. 8) reflects blue light with a low brightness ( $Y=1.8 \%$ in Fig. 7 ), that corresponds to the perceived light when a standard solar cell is observed. On the contrary, red and green colors cannot be easily obtained, since the extension of the gamut is very poor in direction to the 520 and $680 \mathrm{~nm}$ wavelengths.

Figure 9 shows the reflected power at normal incidence in the visible range for points $R, G, B_{1}$ and $B_{2}$ in the gamut diagram. These curves correspond to $t_{A R C}=60,390,75$ and $360 \mathrm{~nm}$ respectively. 


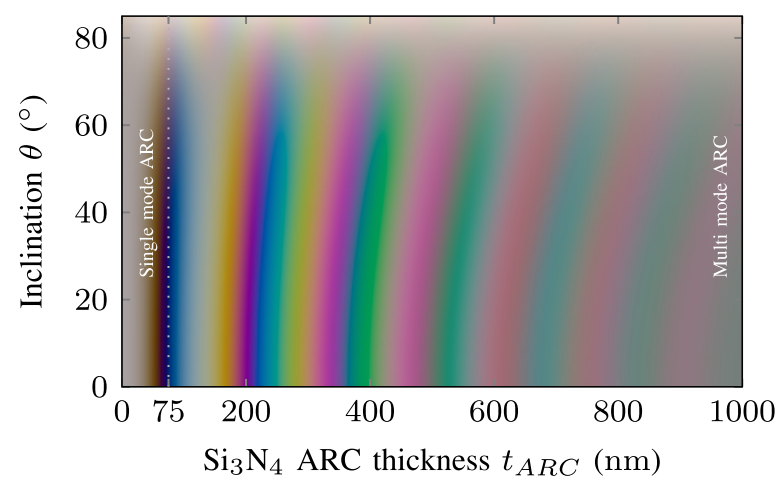

(a) Color after sRGB conversion

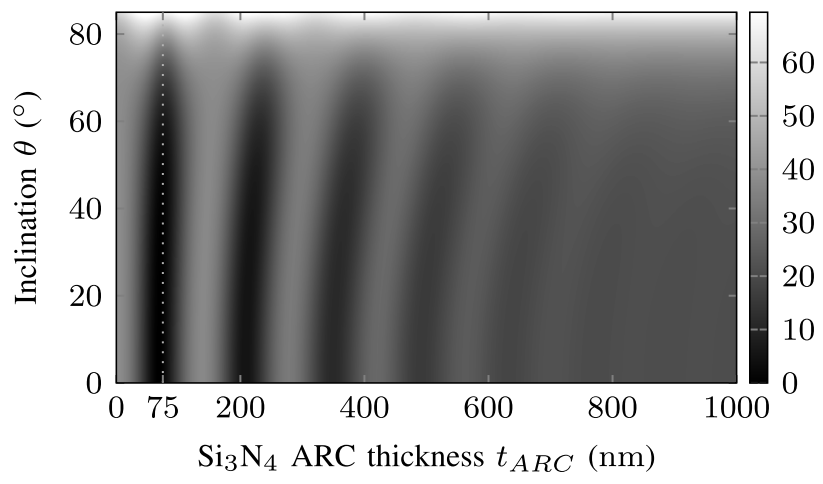

(b) Brightness $Y(\%)$

Fig. 7. Perceived color converted into sRGB (a) and brightness (b) depending on the observation angle and ARC thickness for $\mathrm{Si}_{3} \mathrm{~N}_{4}$.

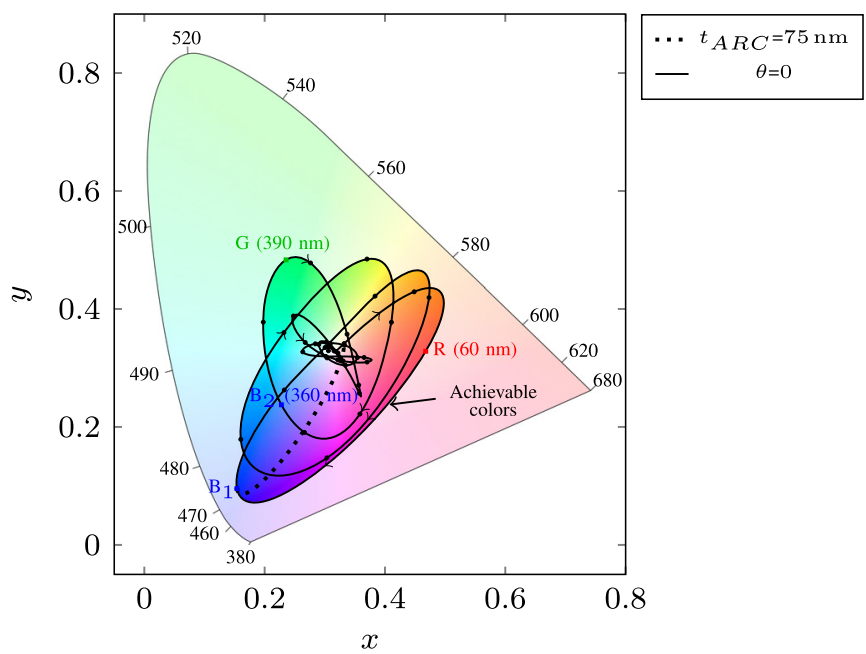

Fig. 8. CIE1931 color space chromaticity for a $\mathrm{Si}_{3} \mathrm{~N}_{4} \mathrm{ARC}$ with an $\mathrm{AM}_{1.5 G}$ irradiance. For $\theta=0$, arrows represent the direction for which $t_{A R C}$ is increasing and round marks correspond to ARC thicknesses multiples of $25 \mathrm{~nm}$.

We can clearly observe that curves for $\mathrm{R}, \mathrm{G}$ and $\mathrm{B}_{1}$ are well accurate to maximize $X, Y$ and $Z$ respectively and obtain red, green and blue solar cells. Indeed, in order to get a green color, the reflected power must be maximum around $\lambda=550 \mathrm{~nm}$ and minimum around $450 \mathrm{~nm}$ and $600 \mathrm{~nm}$ : for this reason, we need a thick multimode ARC, leading to $t_{A R C}=390 \mathrm{~nm}$. It is important to note that the chromaticity diagram is not sufficient to infer the perceived color. Indeed, for the $\mathrm{R}$ and $\mathrm{B}$ points, the brightness is so low $(Y<3 \%)$ that side of a solar cell with a thickness corresponding to $\mathrm{G}(Y=21 \%)$, the human eye will perceive them as almost black. This is confirmed by Figure 7a, even with the sRGB approximation.

Last, the comparison of spectrum for the points $B_{1}$ and $\mathrm{B}_{2}$ shows that both are accurate to get a high value of $X$, but in case of $\mathrm{B}_{2}$ the $Y$ and $Z$ variables are higher (see Eq. (1)), leading to $x$ and $y$ values closer to the $(0.33,0.33)$ point in the chromaticity diagram (Eq. (3)). The reflected power in case of $\mathrm{B}_{2}$ is multiplied by a factor 6.8 , even if this color is less "pure" in terms of blue content.

\subsection{Influence of the irradiance on the perceived color}

In this part, we propose to study whether the irradiance influences or not the color of the reflected light. As the atmosphere absorbs more light in the short wavelengths, the balance between short (blue color) and long wavelengths (red color) varies in disfavor of the blue content when the air mass increases. Consequently, the $\mathrm{AM}_{1 D, G}$ irradiance spectra relatively contain more power in the short wavelengths than $\mathrm{AM}_{3 D, G}$. Here, we propose to calculate the response of the same $\mathrm{Si}_{3} \mathrm{~N}_{4}$ layer as in the previous part for $\mathrm{AM}_{1}, \mathrm{AM}_{1.5}$ and $\mathrm{AM}_{3}$ spectrum (direct and global).

As previously explained, only the simulation for $\theta=0$ is necessary to extract the reachable chromaticity domain for a given single ARC layer. Consequently, after the simulation, we applied a Jarvis based method [28] to extract the convexhull of the data at normal incidence. Results are presented in Figure 10.

The shapes and delimited surfaces by the convex hull of the achievable colors are close for each spectrum. However, each domain is shifted and rotated in order to reduce the coverage in the blue side and increase it in the green and red ones when the air mass increases (i.e. from $\mathrm{AM}_{1 D, G}$ to $\mathrm{AM}_{3 D, G}$ ). This is a consequence of a lower amount of blue photons reaching the surface of the solar cell (Fig. 4). The comparison of the direct and global spectra shows that direct spectra have a lower blue content than the global ones for a given air mass. Consequently, the gamut of a direct spectrum is always shifted in the red direction compared to that one of a global spectrum.

In all cases, the color of a given optical system is not affected a lot by the incident spectrum.

\subsection{Gamuts using silicon nitrides and oxides}

Figure 11 shows the color behavior for both silicon nitrides and oxides taking into account the experimental dispersion curves (Fig. 6).

As we can observe in Figure 11a, the difference between $\mathrm{Si}_{3} \mathrm{~N}_{4}$ and $\mathrm{SiN}_{x}: \mathrm{H}$ (2.08) is quite limited: the stoichiometric nitride has a better extension in the green direction while the standard passivating ARC allows more orange hues. We can also observe that increasing the $\mathrm{Si}$ 


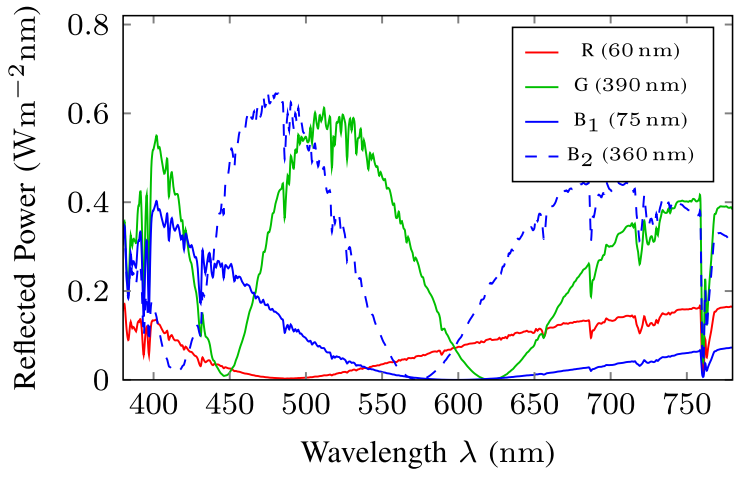

Fig. 9. Reflected power for different thicknesses at normal incidence.

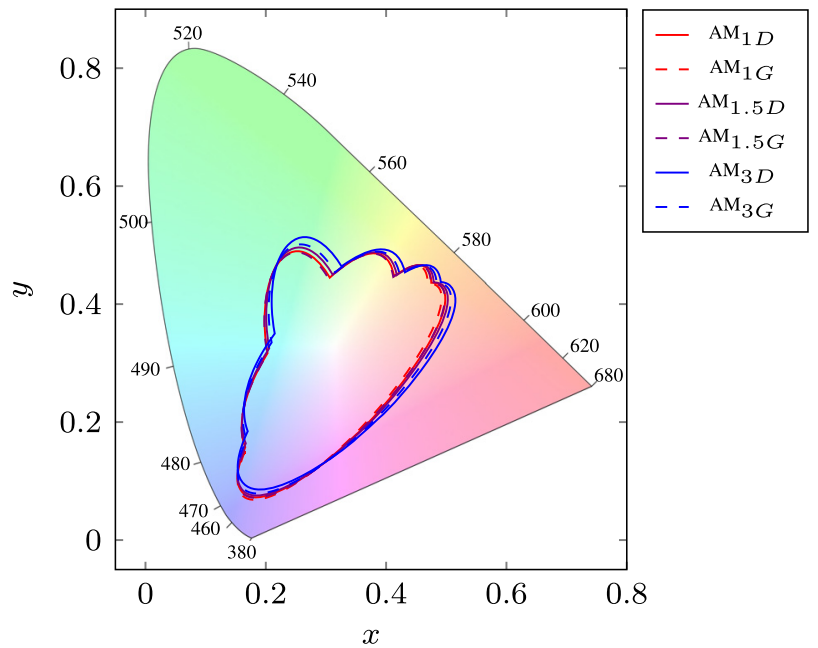

Fig. 10. Influence of the illumination on the perceived color $\left(\mathrm{Si}_{3} \mathrm{~N}_{4} \mathrm{ARC}\right)$ at normal incidence for different irradiances.

content reduces the gamut since the optical index gets closer to the $\mathrm{Si}$ one, leading to a less selective reflection at the front surface.

On the contrary, for sub-stoichiometric oxides (Fig. 11b), increasing the amount of Si increases the surface of the chromaticity diagram in every direction (Fig. 11b). By comparing the behavior of all the $\mathrm{SiO}_{x}$ layers, we can deduce that lowering the optical index reduces the size of the convex hull in every direction. For Si rich oxides we get similar gamuts as for $\mathrm{Si}_{3} \mathrm{~N}_{4}$ and $\mathrm{SiN}_{x}: \mathrm{H}$ since their optical indexes are close. However, in case of silicon oxides, increasing the Si concentration in the ARC helps designing the wanted color, but also increases the parasitic absorption due to a higher extinction coefficient in Figure 6 .

From both figures, we can deduce that the widest gamut corresponds to an optical index close to $n=2$. Consequently, $\mathrm{SiN}_{x}: \mathrm{H}$ is a very interesting layer since it combines a wide range of colors with low absorption and good electrical passivation. This property is compatible with the study of the reflected spectra in the previous part, since the optical index of this standard $\mathrm{SiN}_{x}: \mathrm{H}$ is close to $\sqrt{n_{S i} \cdot n_{\text {air }}}$ (optical index of silicon and air respectively), and so, well adapted to maximize the transmission into the

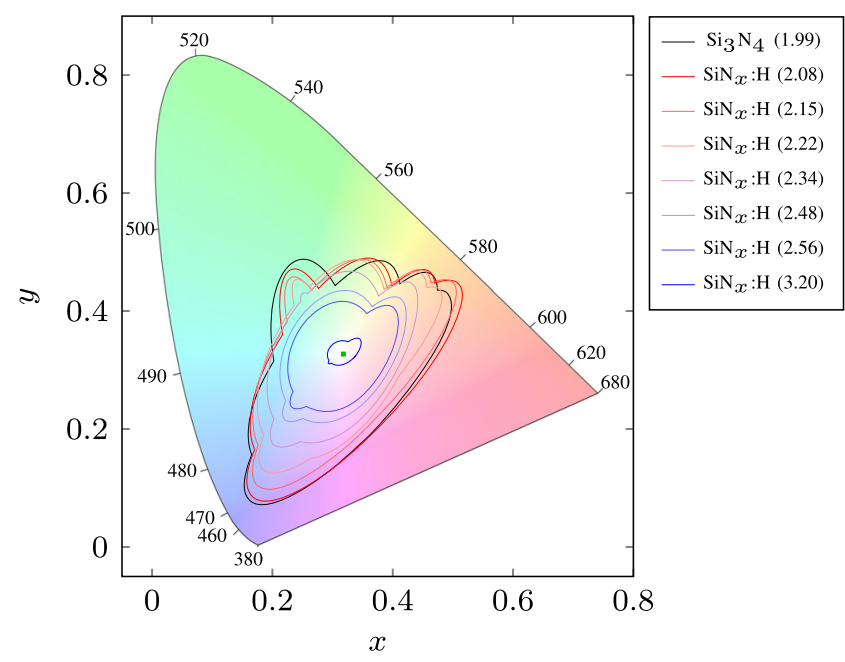

(a) Silicon nitrides

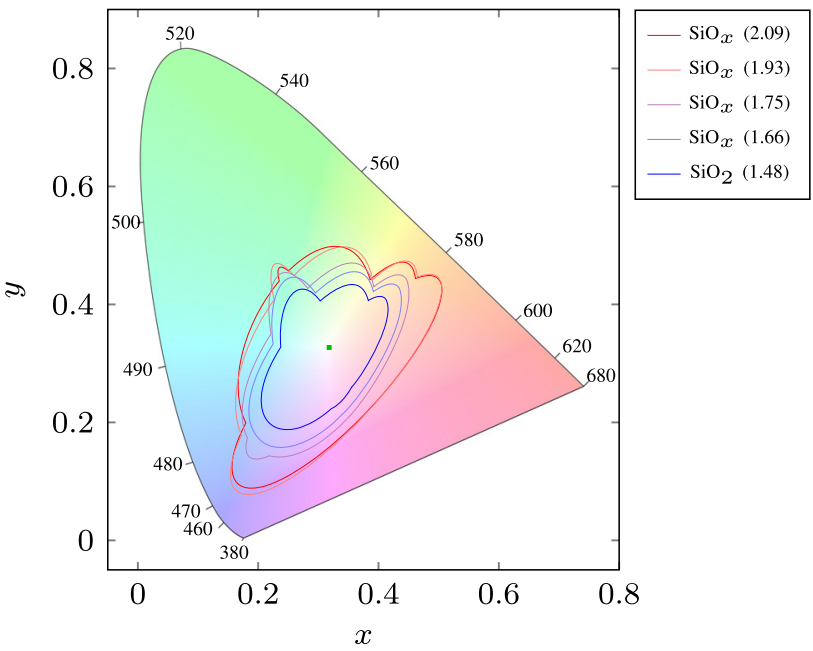

(b) Silicon oxides

Fig. 11. CIE 1931 color space chromaticity for different ARC layers with an $\mathrm{AM}_{1.5 G}$ irradiance (optical index at $\lambda=600 \mathrm{~nm}$ in brackets). The green point in the center of the gamut corresponds to the simulation with no ARC.

active material. As a consequence, it is also accurate to avoid partial reflection of unwanted wavelengths, leading to a better color selectivity.

\subsection{Optical benefits of using a double layer ARC}

In order to extend the reachable gamut, we propose to study a double layer ARC made of both $\mathrm{SiO}_{2}$ and $\mathrm{Si}_{3} \mathrm{~N}_{4}$. This particular combination is not optimized to reduce the reflectivity [29].

The obtained colors with $\theta=0$, approximated in the sRGB domain, are presented in Figure 12a. The corresponding CIE 1931 xy Y color space is shown in Figures 12b and 13. On this second figure, we also add the convex hull of the gamut for both single layer $\mathrm{SiO}_{2}$ and $\mathrm{Si}_{3} \mathrm{~N}_{4}$ ARCs. It must be mentioned that these two layers have the same 


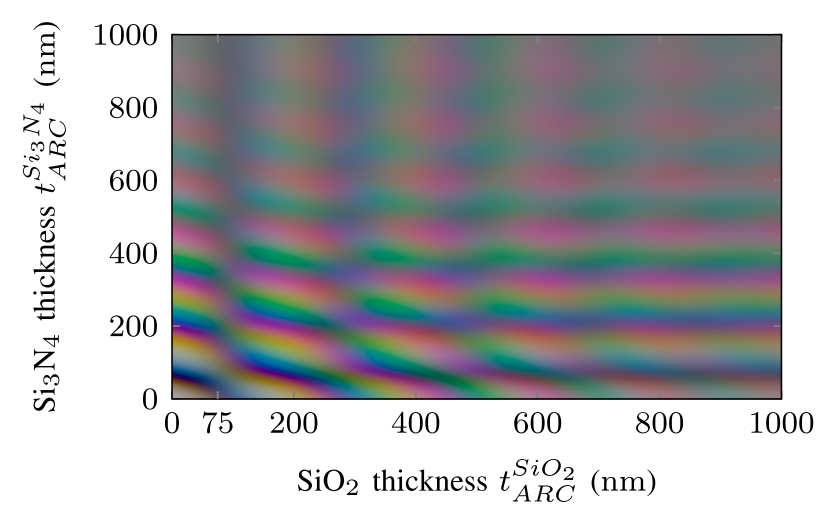

(a) Color after sRGB conversion

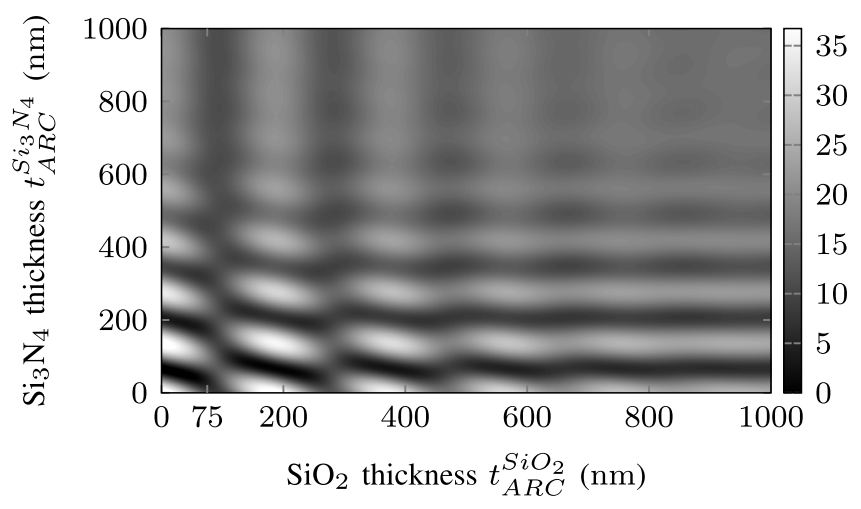

(b) Brightness $Y(\%)$

Fig. 12. Perceived color and brightness converted into sRGB for a $\mathrm{SiO}_{2} / \mathrm{Si}_{3} \mathrm{~N}_{4}$ double layer ARC at normal incidence.

behavior when $t_{A R C}$ increases with the same sequence of colors to define the convex hull, but this latter is smaller for $\mathrm{SiO}_{2}$.

The behavior of the double layer ARC is quite similar as the single one studied previously: when the optical path increases (either in $\mathrm{SiO}_{2}$ or $\mathrm{Si}_{3} \mathrm{~N}_{4}$ ), the system becomes multimode and the color sensitivity decreases, converging toward a gray color. However, in the case of this study, the convergence is quicker with the increase of the silicon nitride thickness than for the silica one, due to its higher optical index. For instance, we observe limited variations of the brightness $Y$ for $t_{A R C}^{S_{3}{ }_{3} N_{4}}>650 \mathrm{~nm}$ while for $t_{A R C}^{\mathrm{SiO}_{2}}>650 \mathrm{~nm}$, the color and the brightness still significantly vary.

The main advantage of using a double layer ARC is the wider extension of the chromaticity (Fig. 13) compared to the single one (Fig. 11), more particularly in the cyan, green, yellow and orange directions. On the contrary, in the red, magenta and blue directions, the chromaticity seems to be limited by the $\mathrm{Si}_{3} \mathrm{~N}_{4}$ layer.

\subsection{Thermal and electrical behaviors}

Figure 14 depicts plots of the cell's temperature as a function of the ARC thickness for $\mathrm{Si}_{3} \mathrm{~N}_{4}$ (solid lines) and $\mathrm{SiO}_{2}$ (dashed lines). In the range $0-200 \mathrm{~nm}$, the cell temperature is strongly sensitive to the ARC thickness regardless of the composition of the ARC layer and the heat coefficient $h_{c o n v}$. The peak

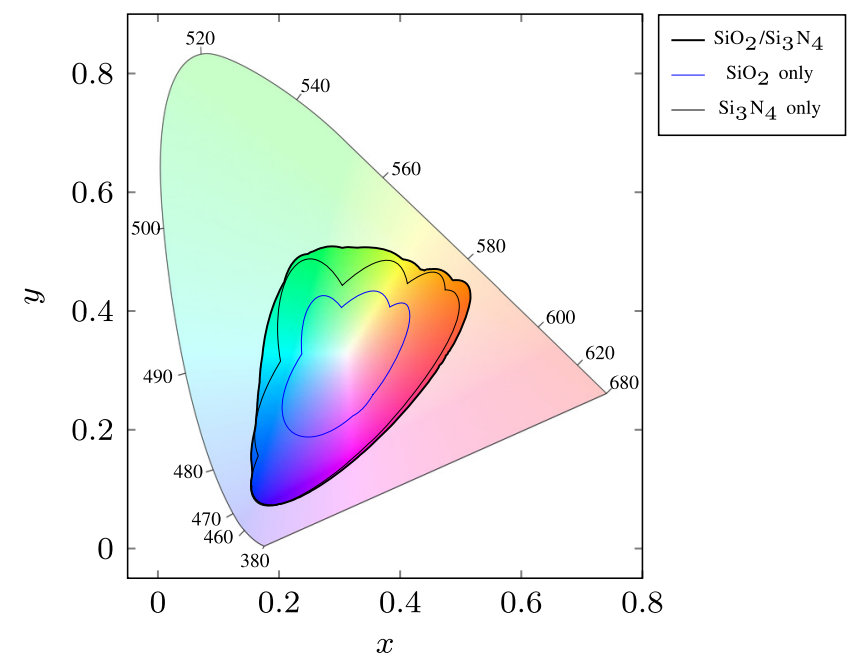

Fig. 13. CIE xyY 1931 color space for a double-stack ARC layer $\left(\mathrm{SiO}_{2} / \mathrm{Si}_{3} \mathrm{~N}_{4}\right)$ with an $\mathrm{AM}_{1.5}$ irradiance.

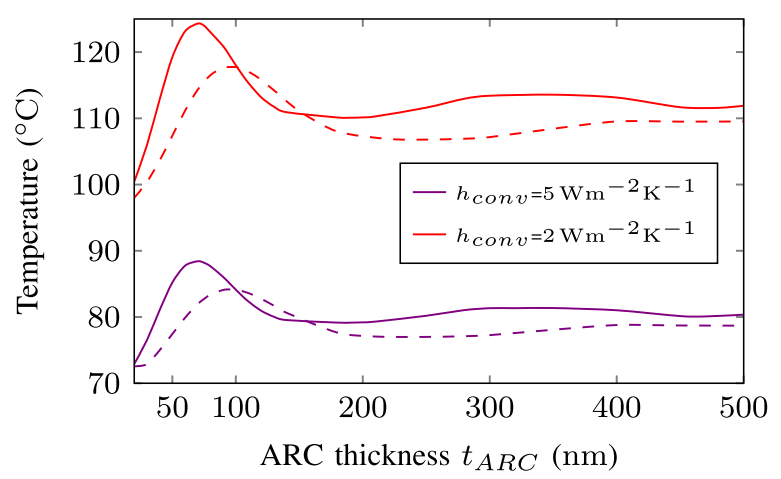

Fig. 14. Solar cell temperature as a function of the ARC thickness under $\mathrm{AM}_{1.5 G}$ illumination. For $h_{c o n v}=+\infty$, temperature is $25{ }^{\circ} \mathrm{C}$ whatever $t_{A R C}$. Solid lines: $\mathrm{Si}_{3} \mathrm{~N}_{4}$, dashed lines: $\mathrm{SiO}_{2}$.

temperature is achieved with $d=70 \mathrm{~nm}$ with a $\mathrm{Si}_{3} \mathrm{~N}_{4}$ coating and about $100 \mathrm{~nm}$ for $\mathrm{SiO}_{2}$. Besides, it is obvious that increasing the heat coefficient induces more cooling of the cell temperature. Beyond $d=200 \mathrm{~nm}$, the temperature shows less sensitivity to the ARC thickness even if it presents a second local maximum around $350 \mathrm{~nm}$ for $\mathrm{Si}_{3} \mathrm{~N}_{4}$ and $400 \mathrm{~nm}$ for $\mathrm{SiO}_{2}$.

To explain the variation of the temperature with the ARC thickness, we display in Figure 15 the variation of the heat sources and sinks in case of $h_{\text {conv }}=5 \mathrm{~W} \cdot \mathrm{m}^{-2} \cdot \mathrm{K}^{-1}$. As we can see, all sources exhibit the same trend: an increase followed by a decrease, and again, an increase and decrease. However, the second peak is less pronounced. In addition, the maximum of the curves does not occur at the same thickness of the ARC. It can also be observed that the heating is dominated by the thermalization, the Joule and the Peltier sources with less contribution for non-radiative recombination. As for cooling, it is mainly due to convection and radiation. The contribution of the Thomson effect is negligible.

It should be pointed out that the thermal sources are higher with $\mathrm{Si}_{3} \mathrm{~N}_{4}$ compare to $\mathrm{SiO}_{2}$, thanks to a lower reflection at the front surface (Fig. 16). Actually, as 

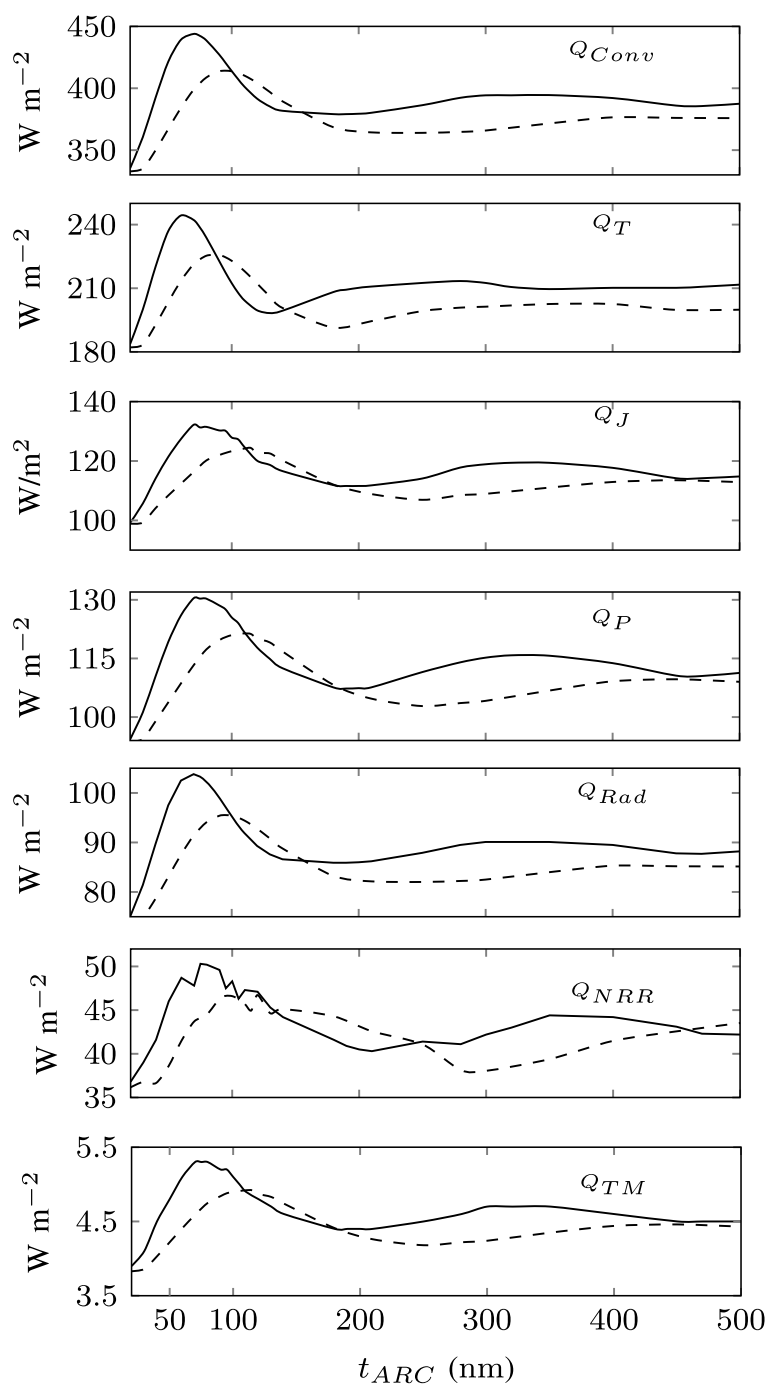

Fig. 15. Heat and sink sources as a function of the ARC thickness (Solid lines: $\mathrm{Si}_{3} \mathrm{~N}_{4}$, dashed lines: $\mathrm{SiO}_{2}$ ).

explained in Section 4.3, the optical index of $\mathrm{Si}_{3} \mathrm{~N}_{4}$ is close to $\sqrt{n_{S i} \cdot n_{\text {air }}}$. The same effect may explain the trend of the Joule and the Thomson sources, since both phenomena are correlated to the photocurrent.

The anti-reflecting layers are usually designed in order to maximize the short-circuit current density $J_{s c}$ at STC where the cell temperature is maintained at $25{ }^{\circ} \mathrm{C}$. This is illustrated in Figure 17 in the case of $\mathrm{SiO}_{2}$ and $\mathrm{Si}_{3} \mathrm{~N}_{4}$ layers. Our own finding indicates that whatever the ARC layer, the optimum thickness does not depend on the heat coefficient $h_{\text {conv }}$. This is readily explained by the fact that the bandgap is weakly influenced by temperature, and so the absorption range. Thus, we find an optimum thickness for $\mathrm{SiO}_{2}$ around $105 \mathrm{~nm}$ and $75 \mathrm{~nm}$ for $\mathrm{Si}_{3} \mathrm{~N}_{4}$. It should be emphasized that the maximum of $J_{s c}$ occurs very close to maximum of the temperature.

Now, considering the electrical conversion efficiency $\eta$ with real environmental conditions as criterion (rather than $J_{S C}$ at STC) leads to different conclusions as illustrated in Figure 18:

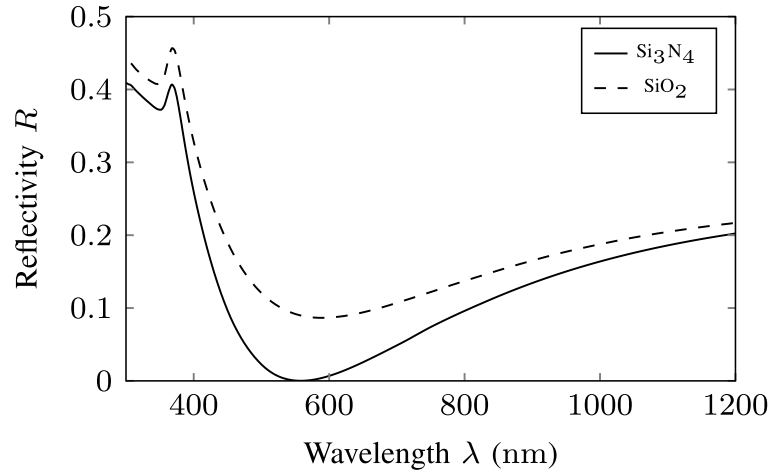

Fig. 16. Reflectivity of the solar cell at the maximum of the thermalization sources.

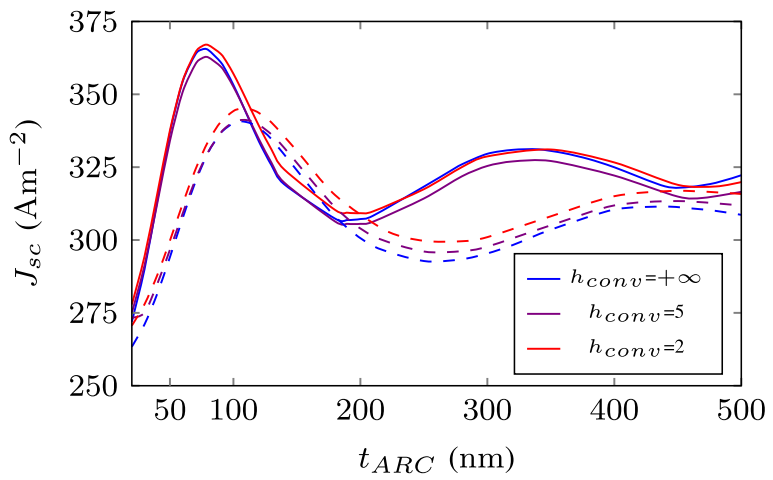

Fig. 17. Short current circuit current density as a function of the ARC thickness (solid lines: $\mathrm{Si}_{3} \mathrm{~N}_{4}$, dashed lines: $\mathrm{SiO}_{2}$ ).

- the decrease of the heat coefficient $h_{\text {conv }}$ lowers the conversion efficiency $\eta$;

- the optimum thickness depends on the thermal environment of the solar cell (Tab. 2) since the thermal heat and sources vary with the ARC thickness (see Fig. 15);

- at high temperature (small value of $h_{\text {conv }}$ in Figure 14), the variation of the conversion efficiency $\eta$ is less pronounced.

Table 2 summarizes the optimal characteristic of the ARC regarding the thermal coefficient. It should be emphasized that calculated values with $h=+\infty$ is equal to those obtained with STC optimization criteria.

We can clearly observe that whatever the ARC material, the optimal thickness must be increased when the cooling conditions deteriorates, i.e. when $h_{\text {conv }}$ decreases, even for realistic conditions with wind $\left(h_{\text {conv }}=5 \mathrm{~W} \cdot \mathrm{m}^{-2} \cdot \mathrm{K}^{-1}\right)$.

\subsection{Color selection and its impact on the thermal and electrical performances}

From previous analysis, we observed that the thickness of an ARC layer can be easily used to tune the color of a solar cell. However, taking into account the thermal effects, we have shown that beyond $t_{A R C}=125 \mathrm{~nm}$, the electrothermo-optical balance of the solar cell leads to similar conversion efficiencies.

This behavior is mainly the consequence of a lower thermalization due to absorption of blue photons, and less heat production, that lowers the conversion efficiency. 

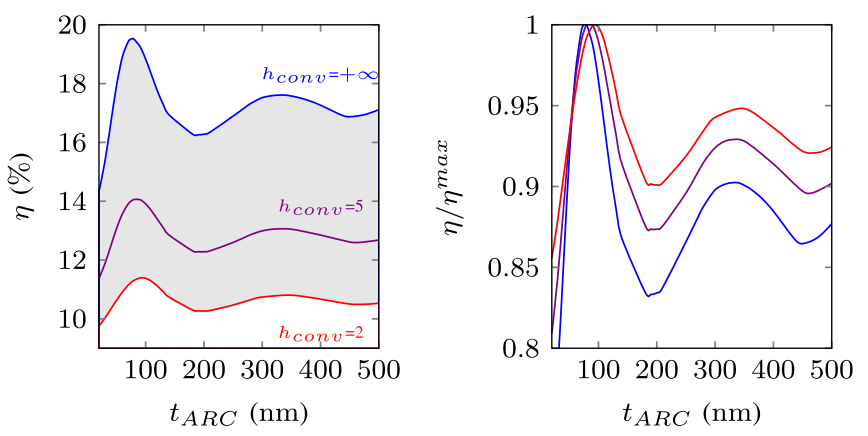

(a) $\mathrm{Si}_{3} \mathrm{~N}_{4} \mathrm{ARC}$
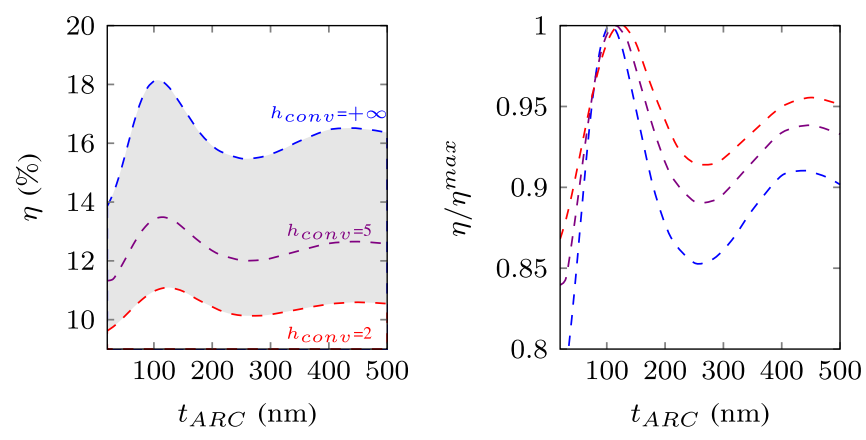

(b) $\mathrm{SiO}_{2}$ ARC

Fig. 18. Absolute and relative conversion efficiencies as a function of the ARC thickness for both $\mathrm{SiO}_{2}$ and $\mathrm{Si}_{3} \mathrm{~N}_{4}$.

In Figure 19, we draw the limit conversion efficiencies with $h=+\infty$ (infinite convection) and $h=2 \mathrm{~W} \cdot \mathrm{m}^{-2} \cdot \mathrm{K}^{-1}$ (no wind), and superimposed the sRGB colors calculated for $\mathrm{AM}_{1.5 G}$ and $\theta=0$. We can observe that the contrast of the colors achieved by the $\mathrm{SiO}_{2}$ ARC is lower than for $\mathrm{Si}_{3} \mathrm{~N}_{4}$, that is compatible with the smaller chromaticity diagram for $\mathrm{SiO}_{2}$ (Fig. 12). In fact, this behavior is a direct consequence of the higher curvature (Fig. 16) of the reflectivity spectrum that helps in color selection. We can also notice that higher conversion efficiencies are achieved for the standard $\mathrm{Si}_{3} \mathrm{~N}_{4}$ layer, making it the ideal candidate to satisfy both performance constraint and color flexibility. In both cases, the peak of the maximum conversion efficiency only leads to dark orange, red, magenta and blue colors (sequence obtained thanks to the gamut in Fig. 8), and the maximum conversion efficiency does not correspond to the darkest blue. Indeed, these dark colors correspond to a high thermalization level that reduces the conversion efficiency due to a high operating temperature. Then, increasing the ARC thickness first leads to a gray color and, then, different colors are available for even thicker ARCs. As a consequence, except for few colors, the maximum conversion efficiency cannot be obtained and it may be difficult to balance the relative brightness between solar cells with different colors. However, for higher ARC thicknesses $\left(t_{A R C}>125 \mathrm{~nm}\right)$, the conversion efficiency is lower but do not vary a lot with the ARC thickness since the ARC also favors the absorption of infrared photons. Then, designers are almost free to tune $t_{A R C}$ and get the color they need since cyan green and yellow colors can be also obtained. This can be done at the cost of a relative
Table 2. Optimal thickness as a function of the heat coefficient to maximize the conversion efficiency.

\begin{tabular}{llll}
\hline & $h_{\text {conv }}=+\infty$ & $\begin{array}{l}h_{\text {conv }}=5 \\
\text { W.m }\end{array}$ & $\begin{array}{l}h_{\text {conv }}=2 \\
\end{array}$ \\
& & $\mathrm{~W} \cdot \mathrm{K}^{-2} \cdot \mathrm{K}^{-1}$ \\
\hline $\mathrm{Si}_{3} \mathrm{~N}_{4}$ & $80 \mathrm{~nm}$ & $80 \mathrm{~nm}$ & $95 \mathrm{~nm}$ \\
$\mathrm{SiO}_{2}$ & $105 \mathrm{~nm}$ & $110 \mathrm{~nm}$ & $120 \mathrm{~nm}$ \\
& & & \\
\hline
\end{tabular}

$5-10 \%$ decrease of the conversion efficiency. If the blue color is necessary for a multi-color BIPV project, one may consider the range 200-225 $\mathrm{nm}$ to balance its brightness with the other colors for $\mathrm{Si}_{3} \mathrm{~N}_{4}$.

Last, the chromaticity diagram (Fig. 8) shows different intersections: for instance, the yellow color at point $(x=0.41, y=0.45)$ can be obtained using a $155 \mathrm{~nm}$ or a $290 \mathrm{~nm}$ thick $\mathrm{Si}_{3} \mathrm{~N}_{4}$ layer. The respective brightnesses are $Y=0.32$ and $Y=0.30$, meaning that the thinner ARC will lead to little bit brighter solar cells, with a slightly lower conversion efficiency (Fig. 19a).

\section{Impact of the EVA and glass for Si flat solar cells}

A realistic solar cell is actually protected by a front glass with an EVA layer to prevent its degradation. This structure may affect both optical and thermal behavior.

\subsection{Optical impact}

From Section 4.3, the best candidate for an extended gamut is expected to correspond to the material for which the transmission in silicon is very efficient. Taking into account the optical index of EVA [30], the optimal index is expected to be around $\sqrt{n_{S i} \cdot n_{E V A}}$. This is what we observe in Figure 20 since the widest gamut is obtained for $n$ between 2.34 and 2.48 for $\mathrm{SiN}_{x}: \mathrm{H}$ layers [21]. Then, the gamut extension in the red and blue directions are very close to the previous study without considering the EVA and glass materials (Fig. 11a), but the extension in the green-cyan and green-yellow directions is better.

The main issue in using $\mathrm{Si}$ rich $\mathrm{SiN}_{x}: \mathrm{H}$ layers is the increase of the parasitic absorption in the ARC layer. A standard ARC layer optimizing the conversion efficiency at STC leads to an optical index close to 2.22 [30]. Then, the gamut is mainly reduced in the red and green directions.

\subsection{Thermal impact of the encapsulation}

The encapsulation of the solar cells affects the thermal balance by adding thermal resistances and modifies the thermal emission of the module. Regarding silicon/EVA/ glass stack structure, the thermal energy balance can be expressed through an effective thermal resistance, $R_{\text {eff }}$, between the cell and the environment [31]:

$$
R_{e f f}=\frac{T_{c}-T_{a m b}}{H}
$$




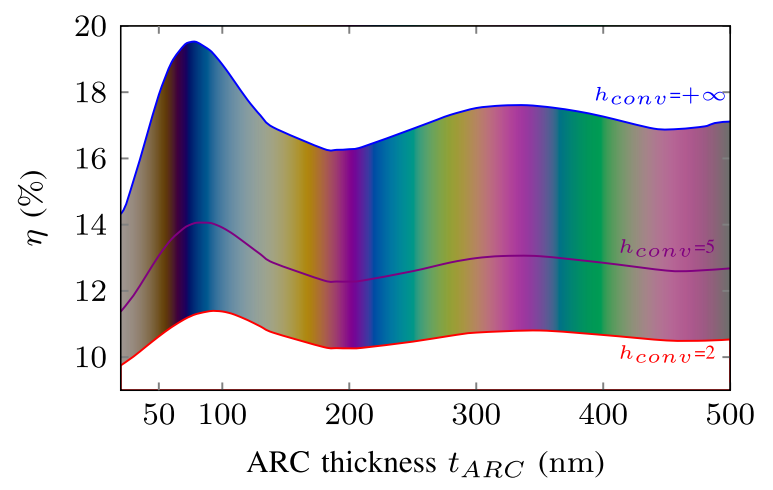

(a) $\mathrm{Si}_{3} \mathrm{~N}_{4}$

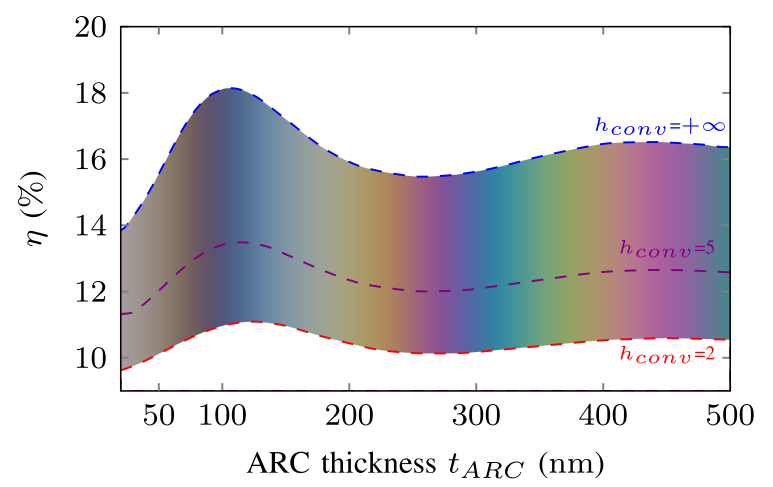

(b) $\mathrm{SiO}_{2}$

Fig. 19. Conversion efficiency and perceived color for different single layer ARC thicknesses (with $\theta=0$ ).

where $H$ is the total heat source, $T_{c}$ the temperature of the cell and $T_{a m b}$ the ambient temperature. It is possible to calculate the value of $R_{\text {eff }}$ through the total of its components for one side of the module:

$$
R_{e f f}=\left(h_{c o n v}+h_{r a d}\right)^{-1}+R_{E V A}+R_{\text {glass }}
$$

where $h_{\text {rad }}$ is the heat coefficient induced by radiative cooling, $h_{\text {conv }}$ represents the convection effect, and $R_{E V A}$ and $R_{\text {glass }}$ are the thermal resistances of glass and EVA layers. With typical EVA and glass characteristics [32], $R_{E V A} \approx 2 \times 10^{-3}$ $\mathrm{W} \cdot \mathrm{m}^{-2} \cdot \mathrm{K}^{-1}, R_{\text {glass }} \approx 2 \times 10^{-3} \mathrm{~W} \cdot \mathrm{m}^{-2} \cdot \mathrm{K}^{-1}$ and $h_{\text {rad }}$ is around $7 \mathrm{~W} \cdot \mathrm{m}^{-2} \cdot \mathrm{K}^{-1}$. When $h_{\text {conv }}>2 \mathrm{~W} \cdot \mathrm{m}^{-2} \cdot \mathrm{K}^{-1}$, the contribution of $R_{E V A}+R_{\text {glass }}$ is less than $3 \%$ in the final value of $R_{\text {eff. This }}$ result is consistent with Weiss et al. [33] and shows that the thermal behavior of a solar module is dominated by heat convection and heat radiation of the solar cell.

Since glass and EVA absorb slightly solar radiation in the UV part which is mostly thermalized in a cell without encapsulation, the heat source, $H$, does not change much. Therefore, only the emission by thermal radiation is modified.

The variation of $h_{\text {rad }}$ caused by the increase of the emissivity of the module from 0.8 to 0.9 [34] induces a variation of $R_{\text {eff }}$ below $10 \%$. This variation has the same impact on the thermal energy balance that a similar variation of $h_{\text {conv }}$ which has been analyzed in Figures 14 and 19 on the non-encapsulated cell. The only case which is not treated correctly through the non-

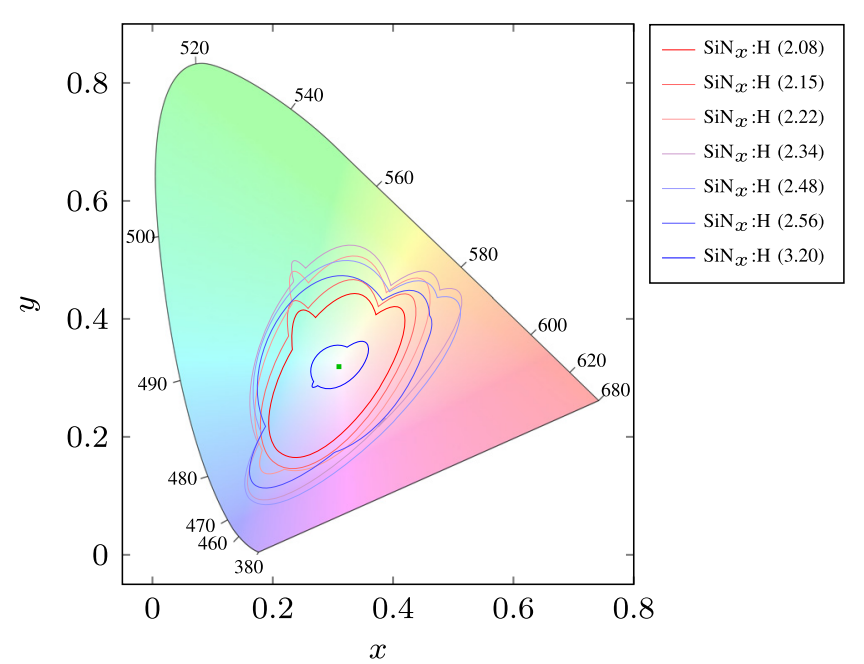

Fig. 20. CIE1931 color space chromaticity for different $\mathrm{SiN}_{x}: \mathrm{H}$ ARC layers with an $\mathrm{AM}_{1.5 G}$ irradiance (optical index at $\lambda=600$ $\mathrm{nm}$ in brackets) when taking the EVA and glass layers into account. The green point in the center of the gamut corresponds the simulation with no ARC.

encapsulated cell is $h_{\text {conv }}=2 \mathrm{~W} \cdot \mathrm{m}^{-2} \cdot \mathrm{K}^{-1}$. Indeed, the increase of the emissivity can slightly decrease the operating temperature. However, the trends described in Figures 14 and 19 are sufficient to understand the implications of such higher emissivity because the impact is limited to only few ${ }^{\circ} \mathrm{C}$. Hence, this analysis can only be improved marginally with the consideration of the glass and the EVA layers whereas texturisation of the surfaces is an interesting challenge to take up.

\section{Conclusion}

In our study, we focused on a solar cell without any encapsulating materials (glass and EVA) on the front surface. However, these materials have a little impact on our conclusions as for colors, the standard ARC suitable for this kind of encapsulation should be accurate for the same reasons as the $\mathrm{SiN}_{x}: \mathrm{H}$ we used. From a thermal point of view, the incorporation of these elements leads to use an effective value of the convection coefficient $h$ slightly higher to that used in our demonstration.

The balance between the conversion efficiency and the possibility to tune the perceived color of a solar cell has been studied. We have demonstrated that increasing the ARC thickness, has a limited impact on the energy production, which implies that the color can be almost freely chosen. This behavior is the consequence of an almost constant thermalization level, and small variations of the thermal sources. When the convection cooling conditions deteriorate, the impact of choosing the solar cell's color decreases further.

Concerning the color properties, we demonstrated that the thinner the ARC, the wider is the inclination for which the perceived color is not degraded. This color is almost independent from the irradiance spectrum, and so the latitude on Earth. For a single layer ARC, the standard $\mathrm{Si}_{3} \mathrm{~N}_{4}$ leads to more contrasted colors compared to 
sub-stoichiometric $\mathrm{SiO}_{x}$ materials. As its optical index is close to that one of the standard $\mathrm{SiN}_{x}: \mathrm{H}$ used for both surface passivation and optical transmission into silicon, we can deduce that this material is also a great candidate to cover a wide range of colors. Last, using a double layer ARC mainly extends the available colors in the cyan, green, yellow and orange directions. These conclusions are obtained for stoichiometric $\mathrm{Si}_{3} \mathrm{~N}_{4}$ and $\mathrm{SiO}_{2}$ which are not the standard materials in PV industry. For more realistic results, it is mandatory to extend the characterization of the optical properties to long wavelength infrared.

Considering the glass and the EVA layers on front of the solar cell slightly extents the gamut around the green color. As for thermal effect, the heat source is not affected since the absorbed light in the active material is marginally impacted. As for cooling, the thermal resistance of glass and EVA is not increased enough to increase significantly the operating temperature.

As a conclusion, taking into account realistic thermal conditions helps in reducing the difference in terms of conversion efficiency between two solar cells with different colors. This may be very handy for BIPV since making drawings or colored patterns with different color solar cells may not influence significantly the overall conversion efficiency.

The authors are thankful to the NanoLyon platform for processing and characterizing different PECVD deposited layers.

\section{Author contribution statement}

All authors have contributed to the writing of the manuscript. More precisely, Romain COUDERC and Mohamed AMARA have refined the home-made code of the $1 \mathrm{D}$ electro-thermo-optical model. Mustapha LEMITI and Fabien MANDORLO worked on the optical behavior for any incident signal and color properties of the simulated solar cells. Felix GERENTON has fabricated and characterized all the $\mathrm{SiN}_{x}$ and $\mathrm{SiO}_{x}$ layers to get realistic estimation of the gamut when simulating the optical stack.

\section{References}

1. B.P. Jelle, C. Breivik, Energy Procedia 20, 78 (2012)

2. A.J. McEvoy, L. Castaner, T. Markvart, Solar cells: materials, manufacture and operation (Academic Press, 2012)

3. E. Skoplaki, J. Palyvos, Sol. Energy 34, 23 (2009)

4. J. Kurnik, M. Jankovec, K. Brecl, M. Topic, Sol. Energy Mater. Sol. Cells 95, 373 (2011)

5. I. Tobias, A.E. Moussaoni, A. Luque, IEEE Trans. Electron Devices 46, 1858 (1999)

6. P. Nubile, Thin Solid Films 342, 257 (1999)
7. H. Nagel, A.G. Aberle, R. Hezel, Prog. Photovolt.: Res. Appl. 7, 245 (1999)

8. B.S. Richards, Prog. Photovolt.: Res. Appl. 12, 253 (2004)

9. M. Li, L. Zeng, Y. Chen, L. Zhuang, X. Wang, H. Shen, Int. J. Photoenergy 2013, 352473 (2013)

10. R. Couderc, M. Amara, M. Lemiti, IEEE J. Photovolt. 6, 1123 (2016)

11. International Commission on Illumination. [Online]. Available at: www.cie.co.at

12. J. Schanda, Colorimetry: understanding the CIE system (John Wiley \& Sons, 2007)

13. International Electrotechnical Commission et al., Multimedia systems and equipment - colour measurement and management - part 2-1: Colour management - default RGB colour space - sRGB, IEC 61966-2-1, Tech. Rep., 1999

14. F. Bernoux, J.-P. Piel, B. Castellon, C. Defranoux, J.-H. Lecat, P. Boher, J.-L. Stehle, Ellipsométrie. Théorie, in Techniques de l'ingénieur. Mesures et contrôle (2003), p. R6490-1

15. D.L. Windt, Comput. Phys. 12, 360 (1998)

16. C.A. Gueymard, Sol. Energy 71, 325 (2001)

17. A.D. Jones, C.P. Underwood, Sol. Energy 70, 349 (2001)

18. H.R. Philipp, J. Electrochem. Soc. 120, 295 (1973)

19. J. Kischkat, S. Peters, B. Gruska, M. Semtsiv, M. Chashnikova, M. Klinkmüller, O. Fedosenko, S. Machulik, A. Aleksandrova, G. Monastyrskyi, et al., Appl. Opt. 51, $6789(2012)$

20. L. Gao, F. Lemarchand, M. Lequime, J. Eur. Opt. Soc. Rapid Publ. 8, 13010 (2013)

21. J.-F. Lelièvre, E. Fourmond, A. Kaminski, O. Palais, D. Ballutaud, M. Lemiti, Sol. Energy Mater. Sol. Cells 93, 1281 (2009)

22. F. Gérenton, F. Mandorlo, E. Fourmond, M. Le Coz, D. Blanc-Pélissier, M. Lemiti, J. Vac. Sci. Technol. A 34, 051201 (2016)

23. D.B.M. Klaassen, Solid-State Electron. 35, 953 (1992)

24. R. Couderc, M. Amara, M. Lemiti, J. Appl. Phys. 115, 093705 (2014)

25. R. Pässler, Phys. Rev. B 66, 085201 (2002)

26. A. Schenk, J. Appl. Phys. 84, 3684 (1998)

27. J. Henrie, S. Kellis, S. Schultz, A. Hawkins, Opt. Express 12, 1464 (2004)

28. R.A. Jarvis, Inf. Process. Lett. 2, 18 (1973)

29. D.N. Wright, E.S. Marstein, A. Holt, Double layer antireflective coatings for silicon solar cells, in Photovoltaic Specialists Conference, 2005. Conference Record of the Thirty-first IEEE (IEEE, 2005), pp. 1237-1240

30. H. Nagel, A.G. Aberle, R. Hezel, Prog. Photovolt.: Res. Appl. 7, 245 (1999)

31. A. Royne, C.J. Dey, D.R. Mills, Sol. Energy Mater. Sol. Cells 86, 451 (2005)

32. G. Notton, C. Cristofari, M. Mattei, P. Poggi, Appl. Therm. Eng. 25, 2854 (2005)

33. L. Weiss, M. Amara, C. Ménézo, Prog. Photovolt.: Res. Appl., 24, $12(2015)$

34. E. Kaplani, S. Kaplanis, Sol. Energy 107, 443 (2014)

Cite this article as: Mohamed Amara, Fabien Mandorlo, Romain Couderc, Félix Gérenton, Mustapha Lemiti, Temperature and color management of silicon solar cells for building integrated photovoltaic, EPJ Photovoltaics 9, 1 (2017) 